\title{
GIUSEPPE PENONE: \\ Por Uma Ontologia da Pele
}

\author{
Marina Andrade Câmara Dayrell \\ Universidade Federal de Minas Gerais (UFMG)
}

\section{RESUMO}

O artista Giuseppe Penone percorre os rastros deixados pelas matérias em que esculpe pera revelar, na escultura, as formas de vida que habitam estas matérias. Conforme formulou Georges Didi-Huberman, fazer escultura é então para Penone, fazer uma escavação. Seu trabalho seria pensado como uma espécie de arqueologia, na medida em que, procedendo pela escavação matérica, ele revela mundos obnubilados. O exercício que aqui propomos é desdobrar criticamente as questões trazidas à tona pelo seu trabalho arqueológico, no intuito de proceder de modo análogo, ou seja, seguir as marcas deixadas na matéria em que ele esculpe ou escava -, para indagarmos, então, qual a natureza destes mundos revelados pelas suas escavações-escultura.

Palavras Chave

Giuseppe Penone, sensível, pele.

\section{Abstract}

The artist Giuseppe Penone follows the traces left in the substances where he sculpts to reveal, in the sculpture, life forms that inhabit those materials. As formulated by Georges Didi-Huberman, making sculpture is to Penone, making a excavation. His work could be thought as a kind of archeology, in which, proceeding by the materical excavation he reveals overlooked worlds. The exercise that we propose here is to critically unfold the issues brought up by his archaeological work in order to proceed in a similar manner: follow the marks left in the material in which he sculpts - or excaves - to inquire, then, what is the nature of those worlds revealed by his excavations-sculpture. 
Key words

Giuseppe Penone, sensuous, skin.

Se aquilo que vive é aquilo que tem pele, é porque vive apenas aquele que é capaz de relacionar-se com a própria aparência [...]. Emanuele Coccia, 2010.

\section{Arqueologia do contato}

O artista Giuseppe Penone percorre os rastros deixados pelas matérias em que esculpe pera revelar, na escultura, as formas de vida que habitam estas matérias. Conforme formulou Georges Didi-Huberman, "Fazer escultura? É então para Penone, fazer uma escavação." (DIDI-HUBERMAN, 2009, p. 55). Seu trabalho seria, assim, uma espécie de arqueologia, na medida em que, procedendo pela escavação matérica, ele revela mundos obnubilados. O exercício que aqui propomos é desdobrar criticamente as questões trazidas à tona pelo seu trabalho arqueológico, no intuito de proceder de modo análogo, ou seja, seguir as marcas deixadas na matéria em que ele esculpe - ou escava -, para indagarmos, então, qual a natureza destes mundos revelados pelas suas escavações-escultura.

Ainda que o artista tenha desenvolvido desenhos a grafite ou instalações ao longo dos seus 45 anos de carreira artística, Penone é, fundamentalmente, um escultor, cuja atenção que dedicada à observação fenomenológica das matérias em que esculpe, impregna seu trabalho com uma irremediável carga filosófica. O desenvolvimento de peças mimetizadas com elementos naturais e a escolha de materiais clássicos da disciplina não compromete no entanto, a profunda contemporaneidade do diálogo estabelecido entre as suas obras e o real, extrapolando, assim, as discussões meta-artísticas. Segundo a curadora Ida Gianelli, o peso do trabalho de Penone estaria no modo como ele reinventa a relação com as disciplinas clássicas: 
Nunca houve uma recusa a priori, da parte do artista, acerca dos instrumentos artísticos tradicionais, ao contrário, junto aos elementos naturais e às práticas menos canônicas, Penone recuperou o uso da fundição em bronze e da escultura em mármore, da terracotta e do desenho a grafite sobre papel, distinguindo-se entre os artistas contemporâneos pela radical reinvenção operada sobre essas técnicas e materiais ${ }^{1}$ (GIANELLI, 2007, p. 12).

A atenção dada à fenomenologia e à filosofia faz com que suas obras estabeleçam um diálogo com a história da arte sem, contudo, subsumir-se a ela. Sobre isto o artista afirma que: "A ideia de utilizar traves de madeira de tipo industrial, geométricas e dar a elas organicidade fazendo aparecer a figura que continham foi pra mim uma reação à ideia minimal e asséptica da arte daqueles anos." (PENONE, 2007, p. 21). ${ }^{2}$

\footnotetext{
${ }^{1}$ Tradução nossa de: "Non c'é mai stato un rifiuto aprioristico da parte dell'artista nei confronti degli strumenti artistici tradizionali, anzi insieme agli elementi naturali e alle pratiche meno canoniche, Penone ha recuperato l'uso della fusione in bronzo e della scultura in marmo, della terracotta e del disegno a grafite su carta, distinguendosi fra gli artisti contemporanei per la radicale reinvenzione operata su quelle tecniche e quei materiali."

${ }^{2}$ Tradução nossa de: 'L'idea di utilizzare delle travi di legno di tipo industriale, geometriche e dare logo organicità facendo apparire la figura che contenevano è stata per me una reazione all'idea minimale e asettica dell'arte di quegli anni."
} 
Figura 1: Albero di 12 metri, 1970, Aktionsraum München

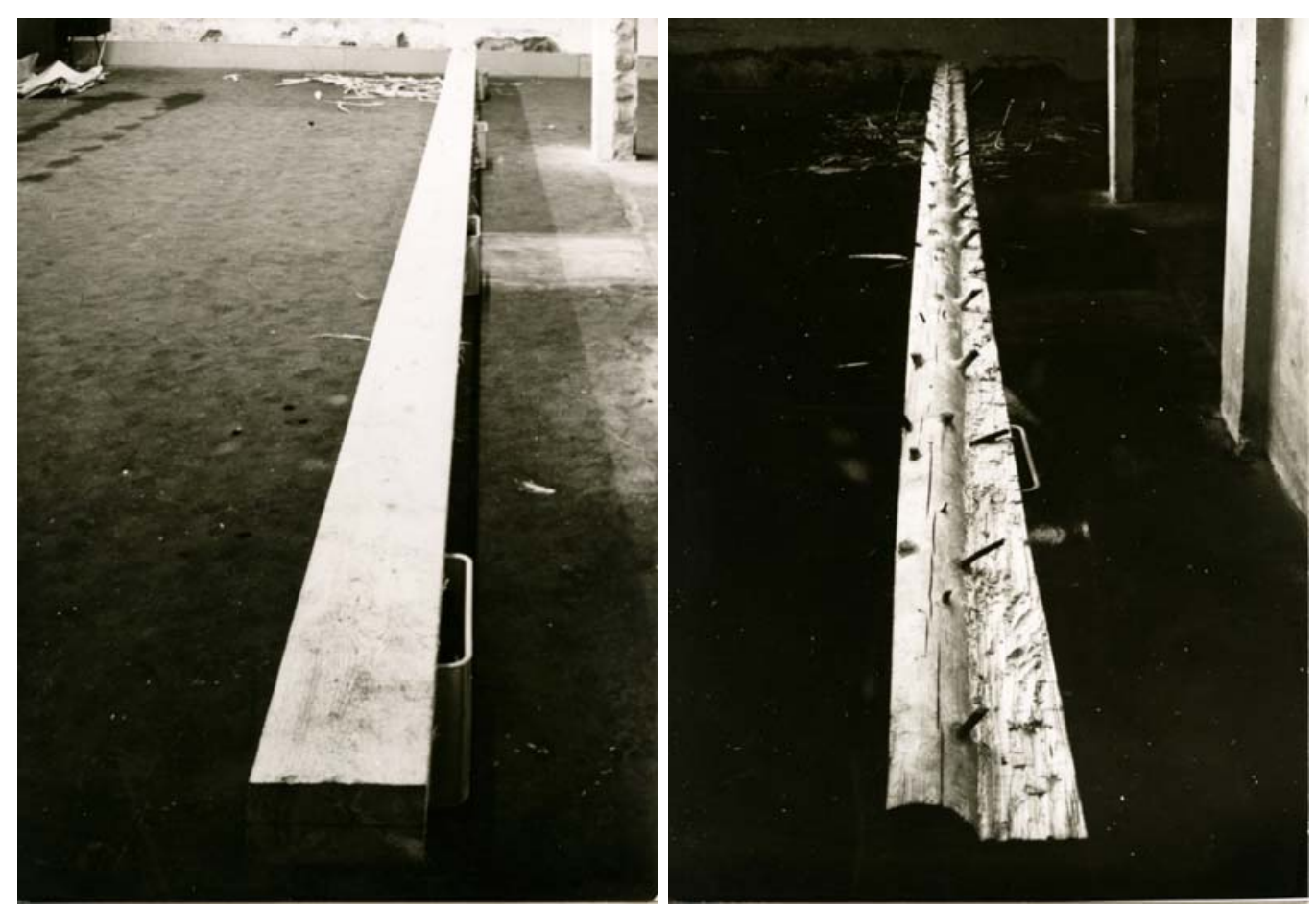

Fonte: Cortesia do artista

Esta organicidade de fato se apresenta, em seus trabalhos, quase como um imperativo. Penone trabalha, initerruptamente a imagem do efêmemero e do movimento o que evoca, segundo o historiador da arte e curador francês Jean-Marc Prévost, uma certa referência ao Barroco ${ }^{3}$ (PRÉVOST, 1989, p. 131-132), referência esta que também é identificada pelo professor e curador francês Didier Semin, por exemplo, na obra Soffio, 1978.

\footnotetext{
${ }^{3}$ Tradução nossa de: "Image de l'éphémère, du moviment, l'on peut évoquer à leur sujet une certaine référence au Baroque."
} 


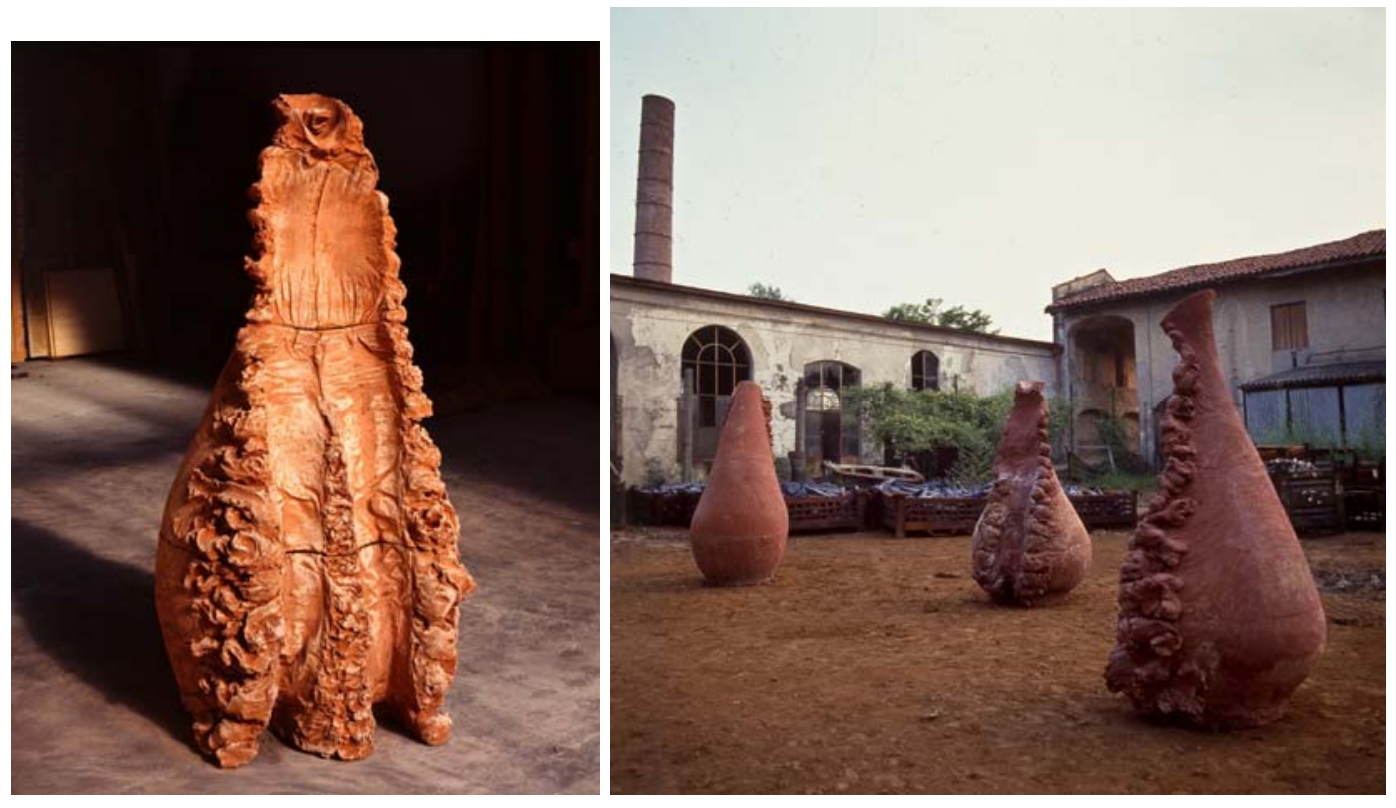

Fonte: Cortesia do artista

Segundo Semin, é possível identificar as dobras e voltas típicas das esculturas barrocas no modo como Penone representa o positivo do volume da respiração do corpo usado como negativo desta obra.

Um diálogo com o classicismo também é identificado pelo fato de Penone ter eleito o bronze em detrimento dos materiais "pobres". Segundo Jean-Marc Prévost, esta escolha "pode sem dúvida fazer pensar na escultura clássica, no início de um classicismo no próprio interior de seu trabalho." ${ }^{4}$ (PRÉVOST, 1989, p. 131). O artista começa a trabalhar com fundição em bronze a partir de 1977 e a utilização que ele faz deste material tem, de fato, diversas reverberações. Ainda que evoque o classicismo, o bronze parece, antes, ter sido escolhido por Penone pela capacidade que ele possui de se contaminar, ou seja, pela aparência que ele dá a si a partir do contágio que sofre por outros elementos e pelo vínculo que o bronze estabelece com o transcedental.

\footnotetext{
${ }^{4}$ Tradução nossa de: "pouvant sans doute faire penser à la sculpture classique, à l'amorce d'un certain classicisme à l'intérieur même de son oeuvre".
} 
O bronze [...] geralmente é um material que assume as cores, na sua pátina, dos vegetais. Uma pátina que é determinada pela chuva, pelo sol, pelos agentes atmosféricos, como pela coloração dos vegetais. [...] $\mathrm{O}$ momento em que foi inventada a fundição em bronze coincide com uma concepção animista da realidade. Todas as coisas, todas as matérias têm espírito, alma, vida [grifo nosso] $]^{5}$ (PENONE, 2007, p. 22).

Efetivamente, ainda que o bronze seja o material que melhor se presta à expressão plástica por conservar até mesmo os menores detalhes da forma moldada, ele é eleito por Penone, ainda segundo Prévost, sobretudo, pela sua reação face ao tempo, sua inelutável corrosão. Ou seja, a impressão que se tem é que todo o domínio da técnica da escultura clássica acaba por subsumir, de algum modo, a uma questão mais central, que nos parece ser precisamente uma busca por algo de imaterial. Escavando continuamente matérias diversas, Penone parece não se contentar, por exemplo, em apresentar, nas esculturas, a heterogeneidade do tempo e seu anacronismo.

Figura 3: Cedro di Versailles, 2000-2003
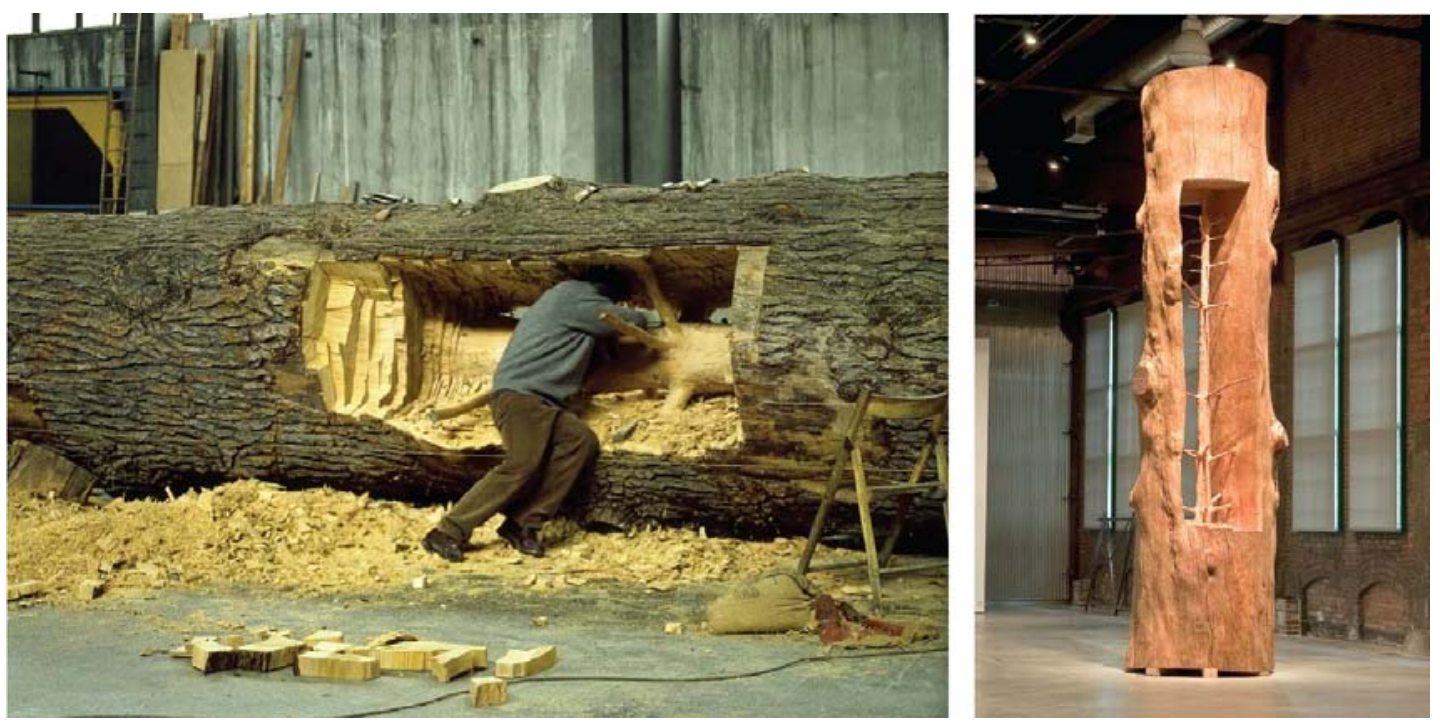

Fonte: Cortesia do artista

\footnotetext{
${ }^{5}$ Tradução nossa de: "Il bronzo [...] in generale è un materiale che assume i colori, nella sua patina, dei vegetali. Una patina che è determinata dalla pioggia, dal sole, dagli agenti atmosferici, come per la colorazione dei vegetali. [...] II momento in cui viene inventata la fusione in bronzo coincide con una concezione animista della realtà. Ogni cosa, ogni materia ha spirito, anima, vita."
} 
Como bem disse Didi-Huberman: "A arqueologia do material não existe separada, aqui, de uma arqueologia do sujeito que a confronte" (DIDI-HUBERMAN, 2009, p. 58). Entretanto, se Penone procedesse retirando extrato por extrato da matéria, mesmo após encontrar esses tempos remotos, se depararia com aquilo com que se deparou Leonardo Da Vinci, ao desenhar uma cebola seccionada ao lado de seus cortes anatômicos. Ou seja, novamente, algo de imaterial.

Na cebola, de fato, a casca é o caroço: não há mais hierarquia possível doravante entre o centro e a periferia. Uma solidariedade perturbadora, baseada no contato - mas também em tênues interstícios -, ata o invólucro e a coisa envolvida. (DIDI-HUBERMAN, 2009, p. 25).

Didi-Huberman chamou de "paradoxo pelicular" esta capacidade que um extrato teria de indiferenciar contentor e conteúdo. Esta extensão do interior ao exterior indica, por fim, a indistinção entre homem e natureza - principal moto das pesquisas de Penone - e pode nos nos levar a pensar, consequentemente, em um recíproco prolongamento do sujeito ao objeto.

Qual seria, - parece se perguntar Penone -, o modo de vida dessa ligação, desse espaço que, ao mesmo tempo, nos une e nos separa dos objetos e da natureza?

\section{O reino do sensível}

Em 2007 Giuseppe Penone e o jovem artista Francesco Vezzoli foram convidados por Ida Gianelli para inaugurar o Pavilhão italiano na $52^{\mathrm{a}}$ Bienal de Veneza, reaberto no Arsenale após oito anos de fechamento, desde sua existência anterior, nos Giardini. Aquilo que os dois artistas, tão distintos técnica e conceitualmente teriam em comum, segundo Gianelli, seria uma certa intenção de "criar formas de arte que valem como pensamentos críticos sobre o existente, sobre 
aquilo que se dá sob a nossa experiência." (GIANELLI, 2007, p. 11). Esta mostra de Penone recebeu o belo título de "Esculturas de linfa" e grande parte dos trabalhos exibidos na ocasião eram, até então, inéditos.

Penone não define como "temas" as árvores, pedras ou vegetais com os quais trabalha, pois, segundo o artista, eles não têm um significado simbólico, mas são, sempre-já, escultura. Também tomada como uma espécie de escultura em si, a questão central que perpassou os trabalhos exibidos nesta mostra foi a pele.

Para a realização de alguns dos trabalhos que expôs naquele ano em Veneza, Penone interviu não somente em árvores, como faz recorrentemente, mas também no mármore e em peles de animais.

\footnotetext{
${ }^{6}$ Tradução nossa de: "creare forme d'arte che valgano come pensieri critici sull'esistente, su ciò che cade sotto la nostra esperienza."
} 
Figura 4: Albero di cuoio 2, 2007

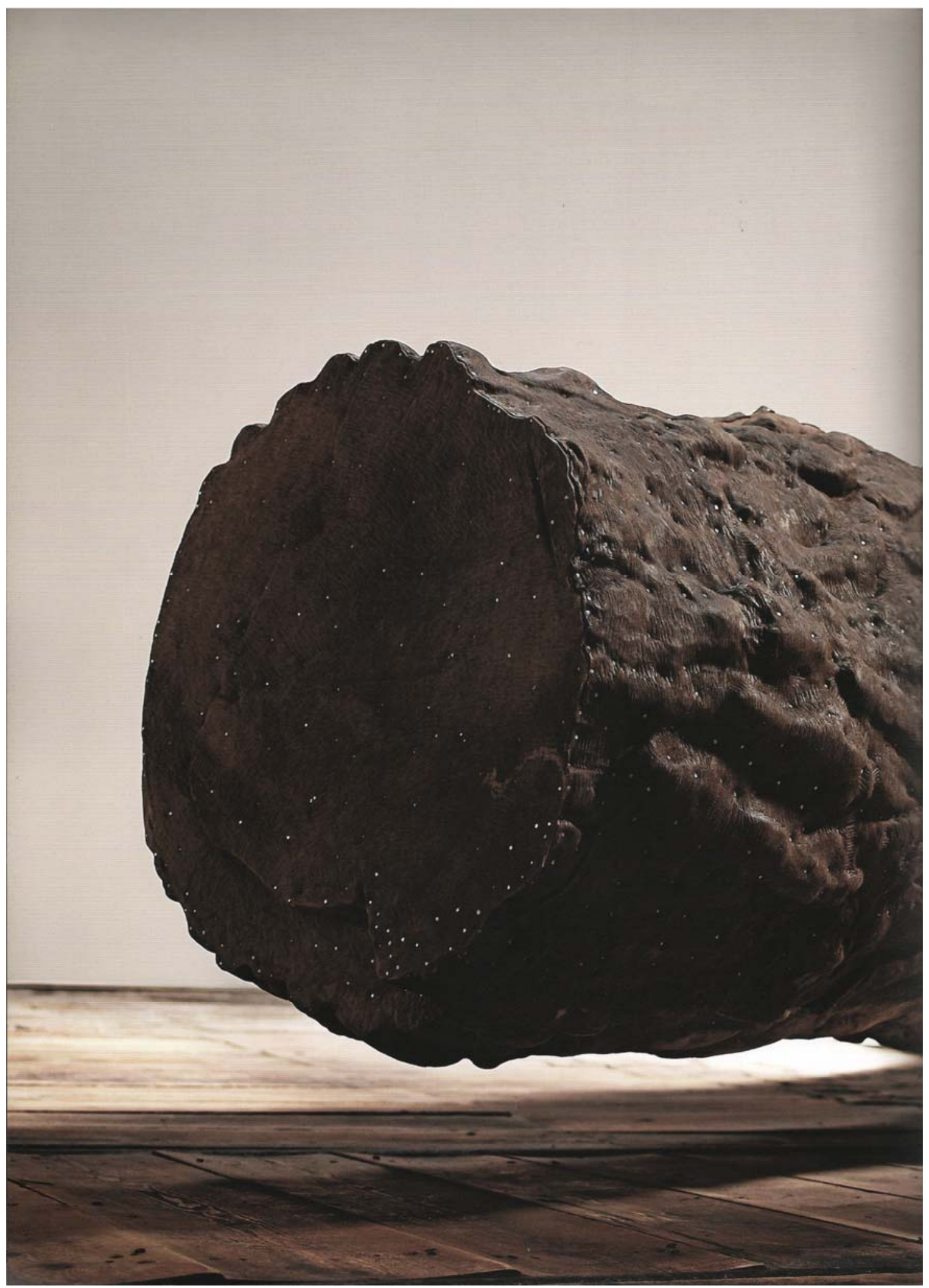

Fonte: PENONE, 2007. 
Seu procedimento consistiu em realizar batimentos em peças de couro curtido sobre cascas de árvores para que delas as peles assumissem a aparência - tanto sua textura quanto sua topografia.

Enquanto a obra Albero di cuoio, 2007, se apresentava como árvores cujas cascas de seus troncos eram forjados por peles de animais, na instalação da obra Pele di marmo-cervello, 2007, sobreposta por Scultura di linfa, 2006, tem-se a analogia entre a seiva que corre no interior das árvores e aquilo que percorre os veios do mármore, indicado pelos percursos de sobreposição matérica que formaram os imensos blocos ali dispostos.

Figura 5: Pele di marmo-cervello, 2007 e Sculture di linfa, 2006

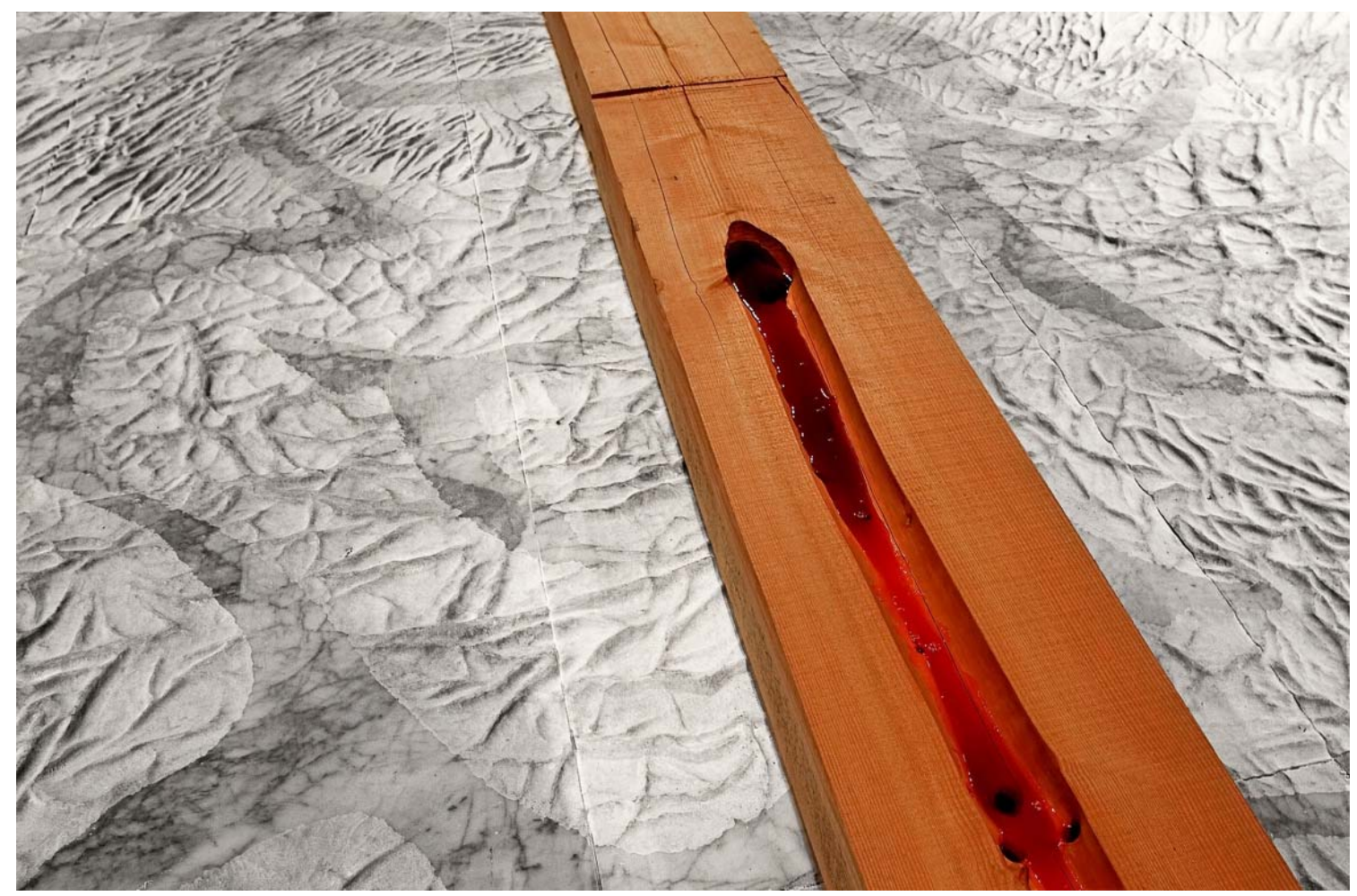

Fonte: Cortesia do artista.

O procedimento realizado sobre o mármore, em Pele di marmo-cervello, 2007, é o mesmo empregado em outros trabalhos voltados para a ideia de 
crescimento, ou seja, compreendendo o desenvolvimento daquela vida como um processo escultórico, Penone opta por não impor a ela nenhuma forma ou volume, e sim por seguir os rastros deixados pelo próprio material em seu processo escultórico de crescimento. Ao percorrer os veios, de acordo com as indicações do próprio mármore, Penone dilata, inclusive, nossa capacidade de identificar modos de vida, pois revela a profunda movimentação daquela que consideramos estática por não sermos capazes de perceber os movimentos - para nós - infinitesimais de seu desenvolvimento. Aludindo aos procedimentos que sugerem tanto as relativizações que Penone realiza sobre as categorias dos reinos animal, vegetal e mineral, quanto o anacronismo inerente a tal relativização, Didier Semin recupera o pensamento do escritor do século XVII, Bernard le Bouyer de Fontenelle, em uma nota que diz: "pela memória de rosa, nunca se viu morrer um jardineiro". (SEMIN, 2007, p. 39). ${ }^{7}$

O dispositivo mimético usado pelo artista no procedimento destes trabalhos vai, no entanto, bem além da complexidade de uma identificação entre os reinos e da consequente relativização temporal, que implica necessariamente um anacronismo, conforme nota Prévost: a "história, ao invés de ser considerada como dada, é considerada como sensibilidade, experiência que nós levamos conosco." 8 (PRÉVOST, 1989, p. 121). Esta busca por formas de vida cuja latência se dá no plano do imperceptível não configuraria, de fato, a busca por uma certa ontologia, que não coincide, no entanto, exclusivamente, com uma transcendência ou eternidade. Esta pesquisa de Penone não o estaria aproximando de uma ontologia da transformação?

Os trabalhos apresentados no Pavilhão italiano de Veneza, em 2007, são desdobramentos de sua interrogação sobre um possível estatuto da pele, como testemunha a série Svolgere la propria pelle, 1970.

\footnotetext{
7 Tradução nossa de: "in base all'ilusione che Fontenelle descrive quando ci suggerisce che, a memoria di rosa, non si è mai visto morire un giardiniere..."

${ }^{8}$ Tradução nossa de: "Mais cette histoire, bien plus que d'être pensée comme donnée, l'est comme sensibilité, expérience que l'on porte en soi."
} 
Figura 6: Svolgere la propria pelle, 1970

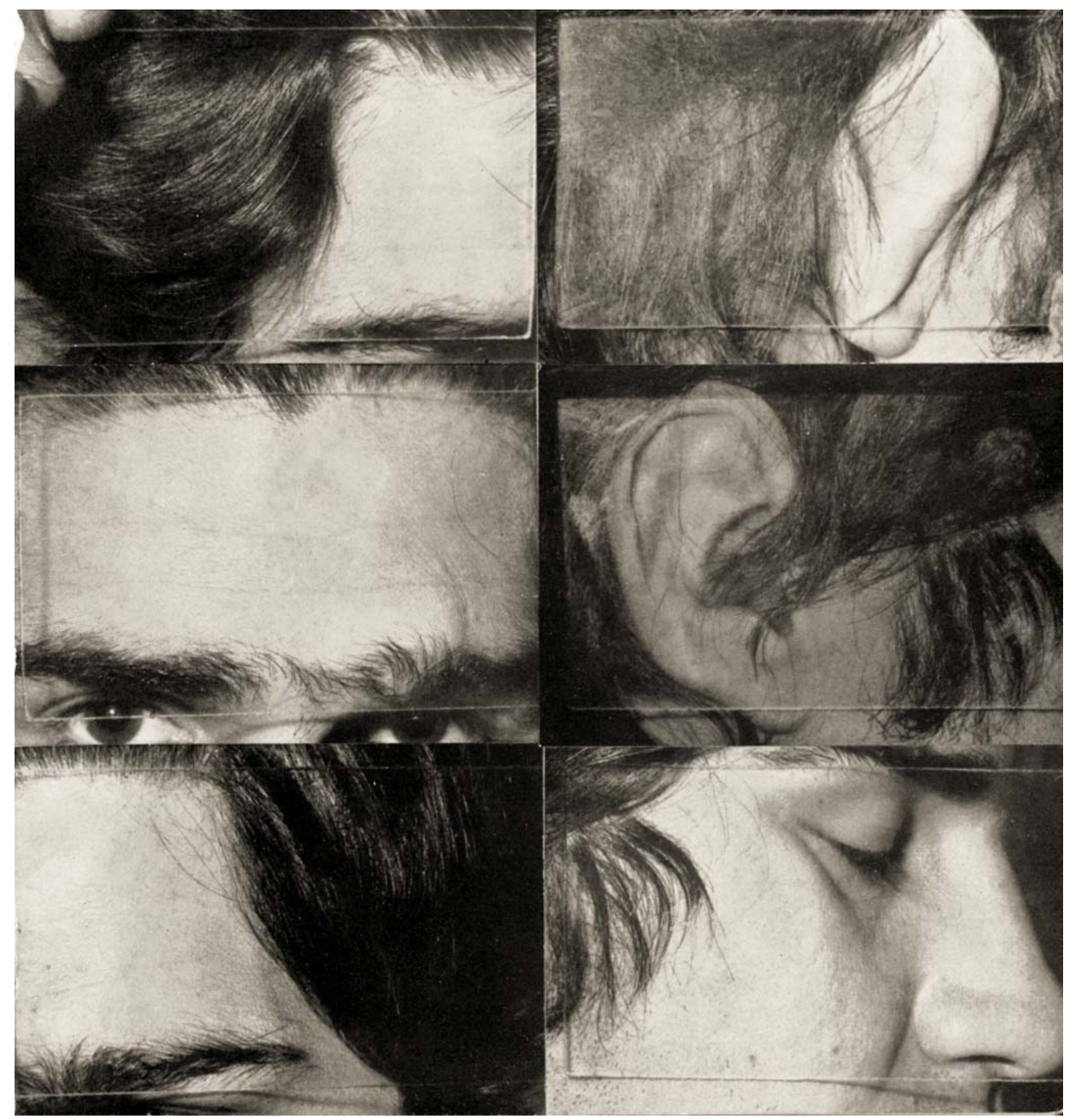

Fonte: Cortesia do artista.

Nesta série Penone pressiona a própria pele contra lâminas de vidro, em um movimento que o aproxima de algum lugar, ao mesmo tempo em que comprime qualquer espaço possível que possa haver entre ele e a superfície transparente.

Didier Semin, em suas reflexões publicadas no catálogo da mostra Esculturas de linfa, sugere qual seria o lugar crítico desta pele interrogada por Penone - seja ela humana, bovina, das árvores ou do mármore: 
[...] pele, não [percebida] como baluarte, mas como zona de contato, em uma concepção erótica [...] [que] já pertence à escultura. [...] Penone imagina a pele na sua complexidade como o positivo de si e o negativo do mundo. Todos estariam de acordo, a priori, em dizer que não há nada, nenhum jogo nem espaço entre a parede do molde e a obra [...] que se presta a extrair. Todavia se não existisse nada, o molde não se distinguiria da peça - há portanto algo, mas algo de infinitamente fino - Marcel Duchamp teria dito inframince, infinitamente sutil - efetivamente quase o nada, mas um nada que influencia tudo. A pele seria então um pouco isso, o espaço entre nós e o espaço do mundo ${ }^{9}$ (SEMIN, 2007, p. 33).

A noção estética contida na escultura se apresenta como algo comum aos processos formadores, independentemente do reino em que se dão: assim como o homem realiza esculturas pelo contato com a matéria, esta, por sua vez, esculpe a si mesma através da sobreposição orgânica que gera o fenômeno de sua formação, na concepção de que crescimento é escultura.

A pele seria, então, aquilo que há de comum entre animais, vegetais e minerais, capaz de reuní-los em um só reino: o reino do sensível. E seria também, o elemento responsável por unir e separar, concomitantemente, os seres viventes e o mundo.

Poderíamos, assim, localizá-la nesse "entre-contato" que é o lugar ambíguo de proteção do ser e abertura ao mundo. Ela mantém a linfa no corpo ao qual esta garante a vida, sendo assim revestimento, cobertura, película ou "definição do corpo

\footnotetext{
${ }^{9}$ Tradução nossa de: "[...] pelle, non come baluardo, ma come zona di contatto, in una concezione erotica [che] appartiene già alla scultura. [...] Penone immagina la pelle nel suo compesso come il positivo di sé e il negativo del mondo. Tutti sarebbero d'accordo, a priori, nel dire che non c'é nulla, nessun gioco né spazio tra le pareti dello stampo e l'opera [...] che ci si appresta a estrarre. Eppure se non ci fosse niente, lo stampo non si distinguerebbe dal pezzo - c'é dunque qualcosa, ma qualcosa di infinitamente fine - Marcel Duchamp avrebbe detto inframince, infinitamente sottile - in effetti quasi il nulla, ma un nulla che influenza tutto. La pelle sarebbe quindi un pó questo, lo spazio tra noi e lo spazio del mondo."
} 
e contentor do nosso pensamento, [...] definição do indivíduo" ${ }^{10}$ (PENONE apud SEMIN, 2007, p. 32). Mas, por outro lado, conforme observa Semin:

[a pele não seria] nem inerte nem impermeável: confim entre um Eu e um mundo que imaginamos distinto, é também espaço de contato, infinitamente sensível e permeável, através do qual estamos no mundo e somos dele parte integrante $^{11}$ (SEMIN, 2007, p. 32).

Se é portanto, o contato - tanto com o dentro quanto com o fora - a característica maior desta pele investigada, parece que Penone, enquanto membro da Arte Povera, teria levado às últimas consequências a proposta de "empobrecimento" que diz respeito precisamente à atenção dada às sensações primeiras. Este lugar para o qual Penone leva suas investigações a respeito da pele deve ser, porém, analisado ainda mais criticamente.

\section{A pele da imagem.}

Este espaço em que o contato se dá, sobre o qual o artista se debruça e do qual se aproxima, comprimindo sobre ele sua pele, é o espaço entre nós - seres viventes - e o mundo. E, como vimos, ainda que seja infrafino, influencia tudo. Se Penone se interroga então sobre "o que é a pele?"12, conforme formulou Didier Semin, (SEMIN, 2007) ele questiona, na verdade, qual é a ontologia deste entre, conforme lemos em suas próprias declarações:

\footnotetext{
10 Tradução nossa de: "pelle" involucro, confine, "definizione del corpo e contenitore del nostro pensiero", "definizione dell'individuo".

${ }^{11}$ Tradução nossa de: "né inerte né impermeabile: confine tra un lo e un mondo che immaginiamo sensibile e permeabile, attraverso cui siamo al mondo e parte integrante di quest'ultimo."

${ }^{12}$ Che cos'è la pelle?: Subtítulo do texto publicado por Didier Semin no catálogo Sculture di linfa, 2007.
} 
A escultura é algo que advém sobretudo através do tocar e do agir, e portanto é muito importante o tato, a relação com a matéria. Tem sempre um espaço entre a mão que toca e a coisa tocada. Pode ser só mesmo o unto da impressão digital, mas existe, é um espaço mínimo que divide o nosso corpo da coisa tocada. ${ }^{13}[\ldots]$ Há sempre um espaço entre a mão e a superfície a qual a mão adere. É a espessura da gordura cerosa da impressão digital. Cobrindo uma superfície com uma espessura de cera se obtém uma pele de cera que possui a dupla impressão da superfície e das mãos. (PENONE, 2007, p. 24-27).

Quais seriam as características deste espaço que Penone insiste em representar através da imagem da pele? Como seria, por fim, a vida deste lugar sensível, da morada das sensações?

O filósofo italiano Emanuele Coccia publicou, recentemente, um livro cujo título é justamente A vida sensível. Nele, Coccia define o sensível como o ser daquilo que ele chama, em sentido amplo, de imagem. Aquilo que ele chama de ser da imagem coincide com uma ontologia do sensível, que, por sua vez, não condiz com uma pura eternidade transcendental, já que, segundo Coccia, a "verdadeira eternidade não é a imortalidade, não é aquilo que nos espera após a morte, nem aquilo que resiste a ela, mas sim aquilo que é transferível e apropriável por qualquer um." (COCCIA, 2010, p. 93). Chamar de ser da imagem a faculdade da sensibilidade não seria, portanto, disparatado, se pensarmos, por exemplo, naquilo que propõe o professor Stéphane Huchet sobre aquilo que é próprio da imagem, ou seja, a "singularidade, linha de partilha da irredutibilidade do símbolo - a diferença - e da realidade mundana do objeto" (HUCHET, 2012, p. 262).

\footnotetext{
${ }^{13}$ Tradução nossa de: "La scultura è un qualcosa che avviene soprattutto attraverso il toccare e l'agire, e quindi è molto importante il tatto, il rapporto con la materia. C'è sempre uno spazio tra la mano che tocca e la cosa toccata. Può essere anche solo l'unto dell'impronta digitale, però esiste, è uno spazio minimo che divide il nostro corpo dalla cosa toccata. [...] C'è sempre uno spazio tra la mano e la superficie a cui la mano aderisce. È lo spessore del grasso ceroso dell'impronta digitale. Coprendo una superficie con uno spessore di cera si ottiene una pelle di cera che ha la doppia impronta della superficie e delle mani."
} 
Aquilo que caracteriza os viventes é, segundo Coccia, justamente a relação que eles estabelecem com as imagens:

[...] a filosofia raramente mediu o peso da sensibilidade sobre a existência humana. Esforçando-se para provar e fundar a racionalidade do homem, procurando separá-lo a qualquer custo do resto dos animais, ela frequentemente esqueceu que todo homem vive no meio da experiência sensível e que pode sobreviver apenas graças às sensações. (COCCIA, 2010, p. 9).

Esta sensibilidade, da qual depende a nossa sobrevivência, não é algo exclusivo do humano, conforme demonstram as obras de Penone. As árvores, assim como outros vegetais e como o mármore, esculpem a si mesmos a partir do contato com os sucessivos depósitos orgânicos, ou seja, a partir do contato da matéria com a matéria. De acordo com aquilo que recupera Coccia, a partir do filósofo grego Alexadre de Afrosísias: "a sensação não é aquilo que transforma um animal em algo humano; ela é, pelo contrário, [...] 'a faculdade através da qual os viventes [...] se tornam animais'" (ALEXANDRE DE AFRODÍSIAS apud COCCIA, 2010, p. 10). É o contato sensível com as imagens que determina a sobrevivência das espécies, pois, qualquer gesto - em sonho ou em vigília - seria vislumbrado e possível somente a partir de uma construção imagética. Aquilo que Stéphane Huchet diz acerca da imagem mental, nos ajuda a compreender o papel essencial desta imagem: ela "representa algo do mundo e, o mundo representa-se nela, já que é sempre através da imagem do mundo que agimos e vivemos." (HUCHET, 2012, p. 226).

A separação entre o homem e os demais viventes seria, portanto, de acordo com a fórmula de Coccia, expressa tão somente na intensidade da sensação e da experiência, ou seja, no grau da relação que o vivente estabelece com as imagens. Esta fórmula não pode, no entanto, ser lida, senão, como aquilo que já foi amplamente explorado e declarado, sobre o ponto que perpassa toda a reflexão de Penone, desde o início de sua produção: ou seja, que homem e natureza não se distinguem. Coccia, ecoando esta indistinção intuída por Penone, a chama de "óbvia distância" puramente relacional. 
[...] a vida humana não se define como um distanciamento do resto dos animais, senão apenas como um aprofundamento dessa mesma vida animal: ela é a vida que levou suas possibilidades [acrescentemos: sensíveis] às últimas consequências. (COCCIA, 2010, p. 60).

Interrogando acerca de uma antropologia do sensível - enquanto o ser da imagem -, Coccia conclui que o "homem não é o animal racional, mas sim o animal que, além de receber imagens, também as desenha e produz." (COCCIA, 2010, p. $60)$.

\section{O modo de vida da imagem.}

Pensar o sensível enquanto ser da imagem é, para Coccia, definitivamente, identificar a sensação enquanto uma forma de vida em si. Se o sensível é o modo pelo qual somos capazes de nos relacionar com o mundo, o estatuto desta imagem é o da trans-formação, ou sej, uma forma que está fora, ao mesmo tempo, do objeto do qual é imagem e de nossa percepção e consciência enquanto sujeitos, fazendo com que esta imagem realize um duplo exílio. E não seria, também este, o lugar reservado para a pele nas obras de Penone? Ou seja, o corpo intermediário, o devir contiguidade entre os seres e o real?

A imagem de que fala Coccia seria, portanto, o ato da transformação: uma forma de trânsito em que algo está concomitantemente além do objeto de que é imagem e aquém da consciência perceptiva do sujeito. Compreendendo que a pele pesquisada por Penone é, claramente, um extrato matérico, ainda que ínfimo, percebemos que suas pesquisas sobre esta pele, enquanto busca de uma ontologia do sensível, possam sugerir o exílio que uma imagem é capaz de realizar em relação ao objeto de que é imagem. Este entre-lugar em que a pele se encontra a torna uma potência receptiva irredutível tanto ao corpo de que é pele, quanto ao mundo com o qual coloca este corpo em contato. Ou seja, esta pele pesquisada por Penone é aquilo que permite o nosso devir sensível para o mundo e o devir sensível do mundo para nós. É um meio, um espaço intermediário - no qual não há 
possibilidade de distinção entre fora e dentro, homem e natureza, sujeito e objeto. E se a possibilidade de devir imagem é aquela de chegar a existir fora de si mesmo, esta possibilidade se dá na pele: representação que nos faz pensar em um terceiro grau ontológico que não está abaixo ou acima do objeto de que é imagem e nem do sujeito que a percebe. Neste meio, as imagens atualizam assim, a solidariedade perturbadora notada por Didi-Huberman ao se deparar com centro e periferia mesclados na cebola de Da Vinci, já que como nota Coccia, a imagem "[...] é a astúcia que as formas encontraram para escapar da dialética alma e corpo, matéria e espírito." (COCCIA, 2010, p. 22).

Somos capazes de estabelecer uma relação com o mundo, - ou, se quisermos, uma relação entre sujeito e objeto -, graças à aparência que o objeto projeta, dele mesmo, no mundo, ou seja, graças à sua imagem, e vice versa. De acordo com Coccia, seria aquilo que o zoologista suíço Adolf Portmann chamou de autopresentação das espécies, ou seja, "não apenas as características óticoacústicas próprias do indivíduo, [...] mas todas as suas manifestações no espaço e no tempo." (COCCIA, 2010, p. 76). O modo como nos autopresentamos, ou seja, nossa aparência seria o substrato por meio do qual cada vivente se dá a ver: que é a pele.

O limite do organismo, o lugar em que ele se diferencia do resto e, ao mesmo tempo, trava contato com ele, "torna-se um órgão", um lugar de existência e de vida, um órgão do ornamento no qual "aquilo que é mais exterior fala daquilo que é mais interior" e em que a interioridade é tão somente a fábula e o mito que nossa forma não para de narrar. Graças à pele, o corpo inteiro se torna simples organe à être vu [...] (COCCIA, 2010, p. 77).

Se conforme afirma Coccia, uma imagem é a existência de algo fora do próprio lugar e se, de acordo com a definição de Huchet, a "imagem sempre é um correlato corporal da expressão, da percepção e do sentido" (HUCHET, 2012, p. 260), a nossa pele seria, então, o receptáculo da nossa aparência, ou seja, lugar em 
que nos alienamos de nós para nos dar a ver enquanto imagens de nós mesmos e assim, devir sensíveis.

Quando Huchet afirma que "toda arte significa a escolha manifesta de um recorte específico - estratégico - da/na realidade visual, certo tipo de gerenciamento das aparências" (HUCHET, 2012, p. 233), pensamos que, se as esculturas elaboradas por Penone não representam senão o modo de vida da matéria esculpida, é para, esculpindo-as, aproximar-se de seus segredos, de suas vidas sensíveis. Penone está certo de que o lugar em que as matérias se fazem imagem, o lugar em que se tornam aparência é a pele. Sua escultura se coloca, portanto, como uma representação da própria matéria, e o artista, revestindo-a com uma nova pele própria, faz com que esta aparência assumida, esse ornamento, diga mais sobre ela que seu estado inicial. Ele esculpe para revestí-la da imagem com a qual ela advêm, então, aparente e sensível para nós e para o mundo, ele esculpe seu trânsito.

\section{Referências bibliográficas}

COCCIA, Emanuele (2010), A vida sensível, Desterro Florianópolis, Cultura e Barbárie.

PENONE, Giuseppe. Convesazione con Giuseppe Penone; SEMIN, Didier. Elogio delle domande semplici. In: GIANELLI, Ida (Org.),Giuseppe Penone. Sculture di linfa. Milano, Electa Mondadori S.p.A., 2007.

DIDI-HUBERMAN, Georges (2009), Ser crânio: lugar, contato, pensamento, escultura, Belo Horizonte: C/ Arte.

HUCHET, Stéphane (2012), Fragmentos de uma teoria da arte, São Paulo, EDUSP.

PRÉVOST, Jean-Marc (1989), “Giuseppe Penone: l'œuvre entre causalité et hasard", In: HINDRY, Ann. Regards sur l'Art Povera, Paris, Artstudio, p.120-135. 